\title{
Prevalence, impact and treatment of generalised anxiety disorder in bipolar disorder: a systematic review and meta-analysis
}

\author{
Antonio Preti, ${ }^{1}{ }^{2}$ Jelena Vrublevska, ${ }^{3}$ Areti Angeliki Veroniki, ${ }^{4}$ Tania B Huedo-Medina, ${ }^{5}$ \\ Konstantinos N Fountoulakis ${ }^{6}$
}

\begin{abstract}
${ }^{1}$ Genneruxi Medical Center, Cagliari, Italy; ${ }^{2}$ Center for Consultation-Liaison Psychiatry and Psychosomatics, University Hospital of Cagliari, Cagliari, Italy; ${ }^{3}$ Department of Psychiatry and Narcology, Riga Stradins University, Riga, Latvia; ${ }^{4}$ Li Ka Shing Knowledge Institute, St. Michael's Hospital, Toronto, Ontario, Canada; ${ }^{5}$ Department of Allied Health Sciences, University of Connecticut, Storrs, Connecticut, USA; ${ }^{6}$ 3rd Department of Psychiatry, School of Medicine, Aristotle University of Thessaloniki, Thessaloniki, Greece

Correspondence to Professor Konstantinos N Fountoulakis, 3rd Department of Psychiatry, School of Medicine, Aristotle University of Thessaloniki, Odysseos 6, Thessaloniki 55536, Greece; kfount@med.auth.gr
\end{abstract}

\begin{abstract}
Question Recent data suggest that anxiety disorders are as often comorbid with bipolar disorder (BD) as with unipolar depression; however, less attention has been paid to comorbidity of anxiety disorders with BD. Generalised anxiety disorder (GAD) is one of the most prevalent anxiety disorders that is highly comorbid with other mental disorders. We carried out a systematic review and meta-analysis to assess the degree of comorbidity between GAD and BD.

Study selection and analysis We searched for all studies, which included primary data concerning the existence of GAD in patients with BD. The literature search strategy, selection of publications and the reporting of results have been conducted with PRISMA guidelines. The meta-analysis calculated prevalence estimates using the variance-stabilising Freeman-Tukey double arcsine transformation. We applied the inverse variance method using both fixed-effects and random-effects models to estimate summary effects for all combined studies. Heterogeneity was assessed and measured with Cochran's 0 and $\mathrm{I}^{2}$ statistics, respectively.

Findings The current meta-analysis analysed data from 28 independent studies and a total of 2975 patients from point prevalence studies and 4919 patients from lifetime studies. The overall random-effects point prevalence of GAD in patients with BD was $12.2 \%(95 \% \mathrm{Cl} 10.9 \%$ to $13.5 \%)$ and the overall random-effects lifetime estimate was $15.1 \%$ (95\% Cl 9.7\% to 21.5\%). Both estimates reported significant heterogeneity $(94.0 \%$ and 94.7\%, respectively).

Conclusions Published studies report prevalence rates with high heterogeneity and consistently higher than those typically reported in the general population. It is believed that comorbid GAD might be associated with a more severe BD course and increased suicidality, and it is unknown how best to treat such conditions. The current meta-analysis confirms that GAD is highly prevalent in $\mathrm{BD}$ and the rate is higher in comparison to those in the general population.
\end{abstract}

\section{BACKGROUND}

Comorbidity has been described as the presence of more than one disorder in a person in a defined period of time. ${ }^{1}$ Psychiatric comorbidity is reported to be a common phenomenon in patients with bipolar disorder (BD). The rates of lifetime comorbidity in $\mathrm{BD}$ seem to be higher than $50 \%{ }^{2}{ }^{3}$ and may reach even $70 \%{ }^{4-8}$ Taking into account the existing substantial overlap between the symptoms of acute BD and those from other mental disorders, it is recommended to diagnose a comorbid mental disorder only if it occurs before the onset of bipolar illness or during periods when mood symptoms are not prominent. ${ }^{9} 10$ This is especially important concerning anxiety disorders which share many symptoms with mood disorders and often put the question whether it is high comorbidity or different facets of the same spectrum of disorders. It is estimated that anxiety disorders are the most frequent disorders in the general population. ${ }^{11}$ In various studies, generalised anxiety disorder (GAD) comorbid with another mental disorder has been reported at rates equal to $7-32 \%{ }^{12}$ Until two decades ago, most research had focused on the comorbidity between unipolar depression and anxiety disorders. Less attention has been paid to comorbidity of anxiety disorders with $\mathrm{BD}$.

There is convincing evidence that the rates of anxiety disorders are higher among patients with BD compared with their rates in the general population. ${ }^{7}$ Recent data suggest that anxiety disorders are as often comorbid with BD as with unipolar depression. ${ }^{13}$ Clinically, it is crucial to identify and treat comorbid anxiety disorders because of their contribution to poor treatment response and recovery, fewer periods of euthymia and higher rates of substance abuse and suicide attempts. ${ }^{12}{ }^{14-16}$ It is also important to define the comorbidity rate of anxiety disorders in patients with $\mathrm{BD}$ because the treatment of this comorbid condition is not straightforward and puts the patient at a high risk to a number of adverse events including higher risk to medication-induced switch.

\section{OBJECTIVE}

The aim of the current study was to systematically review the literature for data concerning the comorbidity of GAD and $\mathrm{BD}$. We conducted a meta-analysis of the data retrieved so as to arrive at point and lifetime rates of comorbidity.

\section{STUDY SELECTION AND ANALYSIS}

\section{Review of the literature}

Two authors (KNF and JV) developed the search code investigating the comorbidity of GAD with $\mathrm{BD}$ with searches in PubMed/MEDLINE, from inception until 6 June 2015.

One reviewer (KNF) screened the titles and abstracts resulting from the search strategy, while a second reviewer (JV) verified. When the inclusion of a study was unclear, the full-text article was screened. This review followed the recommendations of the Preferred Items for Reporting of Systematic Reviews and Meta-Analyses (PRISMA) statement. ${ }^{17} \mathrm{~A}$ checklist concerning the PRISMA procedure is included in the online supplementary appendix.

\section{Literature search key words}

The PubMed database was searched using a combination of search terms as follows:

"bipolar[All Fields] OR ("bipolar disorder"[MeSH $\quad$ Terms] OR ("bipolar"[All Fields] AND "disorder"[All Fields]) OR "bipolar 
disorder"[All Fields] OR "mania"[All Fields]) OR ("bipolar disorder"[MeSH Terms] OR ("bipolar"[All Fields] AND "disorder"[All Fields]) OR "bipolar disorder"[All Fields] OR "manic"[All Fields]) AND (generalized[All Fields] AND ("anxiety disorders"[MeSH Terms] OR ("anxiety"[All Fields] AND "disorders"[All Fields]) OR "anxiety disorders"[All Fields] OR ("anxiety"[All Fields] AND "disorder"[All Fields]) OR "anxiety disorder"[All Fields])) OR GAD[All Fields]." Also, the reference lists of books and reviews were scanned. ${ }^{18-20}$

\section{Criteria for study selection}

- English language

- Studies which included primary data concerning the existence of $\mathrm{GAD}$ in patients with $\mathrm{BD}$

\section{Meta-analysis}

\section{Data abstraction and quality assessment}

Two authors (JV and KNF) used a standardised coding system previously pilot tested to extract the following data from the articles: authors' names, publication year, location, sample size, criteria for diagnosis, procedure for diagnosis (whether this was conducted by standardised interview, semistandardised interview or clinical decision), number of cases with $B D$, number of cases with $G A D$, number of cases with any other diagnostic group which had been used as comparison. Relevant data from each study were abstracted by one reviewer (KNF) and verified by a second reviewer (JV). Discrepancies in scoring were resolved through discussion.

\section{Data synthesis and implementation}

Prevalence estimates were calculated using the variance-stabilising Freeman-Tukey double arcsine transformation. ${ }^{21}$ The double arcsine transformation is known to outperform other proposed methods of prevalence estimates. ${ }^{22}$

We applied the inverse variance method using both fixed-effects and random-effects models to estimate summary effects for all combined studies. It has been shown that the inverse-variance weight in fixed-effects meta-analysis is suboptimal when dealing with data with low prevalence. ${ }^{23}$ In each meta-analysis, we synthesised the prevalence estimates using the double arcsine transformation, and then we backtransformed the pooled estimate to a proportion, so as to have an interpretable scale. In the random-effects model, we estimated the heterogeneity variance among studies using the empirical Bayes estimator, ${ }^{24}$ also known as the Paule-Mandel estimator, ${ }^{25}$ and its $95 \% \mathrm{Cl}$ using the 0-Profile method. ${ }^{26}$ Under the random-effects model, we also used the Knapp and Hartung ${ }^{27}$ method as an alternative to infer about the summary effect. The method estimates the uncertainty for the overall treatment effect based on the t-distribution (with 'number of studies-1' degrees of freedom) and a weighted extension of the inverse variance formula accounting for the between-study heterogeneity. Heterogeneity was assessed with Cochran's 0 and $\mathrm{I}^{2}$ statistics. ${ }^{28} \mathrm{~A}$ low $\mathrm{p}$ value (ie, $p<0.10$ ) of the 0 statistic that variation in the study-specific effect estimates is due to heterogeneity beyond chance. For $1^{2}$, values between $0 \%$ and $40 \%$ might not be important; $30-60 \%$ may represent moderate heterogeneity; $50-90 \%$ may represent substantial heterogeneity and $75-100 \%$ may represent considerable heterogeneity. ${ }^{29}$

We presented fixed-effects and random-effects summary estimates along with a corresponding $95 \% \mathrm{Cl}$ for each analysis in forest plots. Differences between fixed-effects and random-effects estimates suggest that there are differences between the point estimates from smaller and larger studies: such differences were examined in outcomes with 10 or more studies using funnel plots and Egger's ${ }^{30}$ and Begg's regression test. ${ }^{31}$

The Baujat plot was used to detect the contribution of each study to the overall heterogeneity. ${ }^{32}$ The Baujat plot reports on the $x$-axis the contribution of each study to the overall heterogeneity, while on the $y$-axis is reported the influence of each study on the overall treatment effect, calculated as the standardised difference of the overall treatment effect with and without each study. To control for adequacy of the models and the identification of outliers, we used the radial plot ${ }^{33} 34$ and the standardised residuals plot $^{35}$ in relation to the random-effects model. For a random-effects model, the radial plot shows the sampling variance of the observed effect size or outcome against the amount of heterogeneity as estimated based on the model. As far as the standardised residuals plot is concerned, if a study fits the model, its standardised residual follows (asymptotically) a standard normal distribution. A large standardised residual (>2 SD) for a study therefore may suggest that the study does not fit the assumed model (ie, it may be an outlier). When possible, differences in prevalence according to characteristics of individuals or of studies were estimated by comparing prevalence between subgroups of studies. We used metaregression techniques to evaluate the impact of clinical variables: gender ratio, mean age of the sample, diagnostic procedure. Subgroup analysis was applied to estimate the impact of study characteristics: subtypes of $B D$, on prevalence rates of generalised anxiety.

Meta-analysis was carried out with the 'meta' package ${ }^{36}$ and the 'metafor' package ${ }^{35}$ running in R V.3.0.2. ${ }^{37}$

\section{FINDINGS}

The initial MEDLINE search retrieved 1300 articles, whereas another 14 papers were identified from other sources. Eventually 30 papers were eligible $(7$ studies from the MEDLINE search and 23 from other sources). Fifteen of them included data with cross sectional prevalence. $^{6}{ }^{12}{ }^{38-50}$ However the Simon et al studies ${ }^{1249} 50$ include up to the first 500 patients from the STEP-BD study while the Otto et a $a^{46}$ includes the first 1000 patients from the same study. Therefore in the current analysis only the Otto et al. ${ }^{46}$ study was utilized. Thus 13 studies were eligible for the analysis for point prevalence. ${ }^{6}{ }^{12}{ }^{38-48}$ One of the Simon et al studies ${ }^{12}$ was used only to calculate the comorbidity rates separately for BD-I and BD-II patients. Another 19 papers contained data concerning the lifetime prevalence ${ }^{2} 6 \quad 12-14 \quad 16 \quad 47 \quad 48$ 51-61 and were included in the analysis. However, the Rihmer et al., $2001^{58}$ reported data that also were reported in Szadoczky et al., 1998, ${ }^{60}$ and data from Rihmer et al., $2001^{58}$ was used only to calculate the comorbidity rates separately for BD-I and BD-II patients. Overall data from 28 independent studies were used in total. The PRISMA flowchart is shown in figure 1 in the main manuscript. In detail the PRISMA flowchart is shown in figure 1 while a list of the studies used for the analysis can be found in the web appendix. Sample sizes varied widely across studies $(\mathrm{N}=20-918$ in studies with point prevalence estimates; 24-1411 in studies with lifetime estimates) and females were overrepresented. The mean age was 37 (range 30-43) in point prevalence studies and 38.9 (range 30-44) in lifetime studies (figure 2). In studies with point prevalence estimates, the Structured Clinical Interview for Diagnostic and Statistical Manual of Mental Disorders (DSM) - SCID was applied in 12 studies to derive the diagnosis, and just one applied the Schedule for Affective Disorders and Schizophrenia-Lifetime version (SADS-L; table 1). In studies with lifetime estimates, the SCID was applied in 10 studies, while 9 studies applied other standardised procedures to draw the diagnosis (see table 2).

The fixed-effects point prevalence estimate of GAD in patients diagnosed with $\mathrm{BD}$ was $9.6 \%(95 \% \mathrm{Cl} 8.5 \%$ to $10.7 \%)$. The overall random-effects point prevalence estimate of GAD in patients diagnosed with $\mathrm{BD}$ was $11.5 \%$ (95\% Cl $6.6 \%$ to $17.4 \%$; figure 3). Heterogeneity was substantial: $\left.\right|^{2}=94.0 \%(95 \% \mathrm{Cl} 91.2 \%$ to $95.9 \%$; table 3$)$. Reanalysis of data without one outlier study gave a fixed-effects point prevalence estimate equal to $12.2 \%(10.9 \%$ to $13.5 \%)$, with no statistically significant change in the random-effects estimates: $12.9 \%(8.2 \%$ 

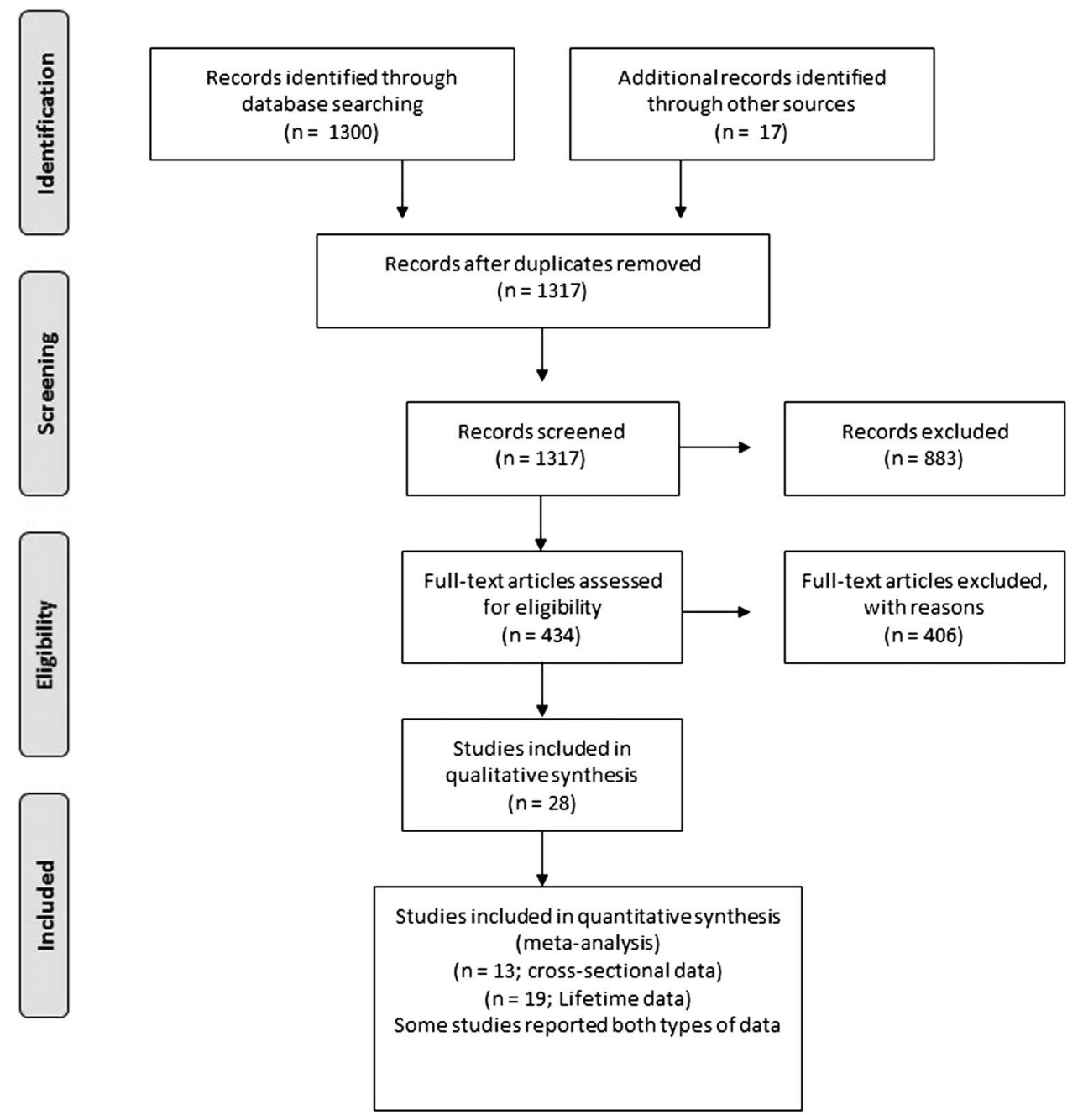

Figure 1 The PRISMA flow chart.
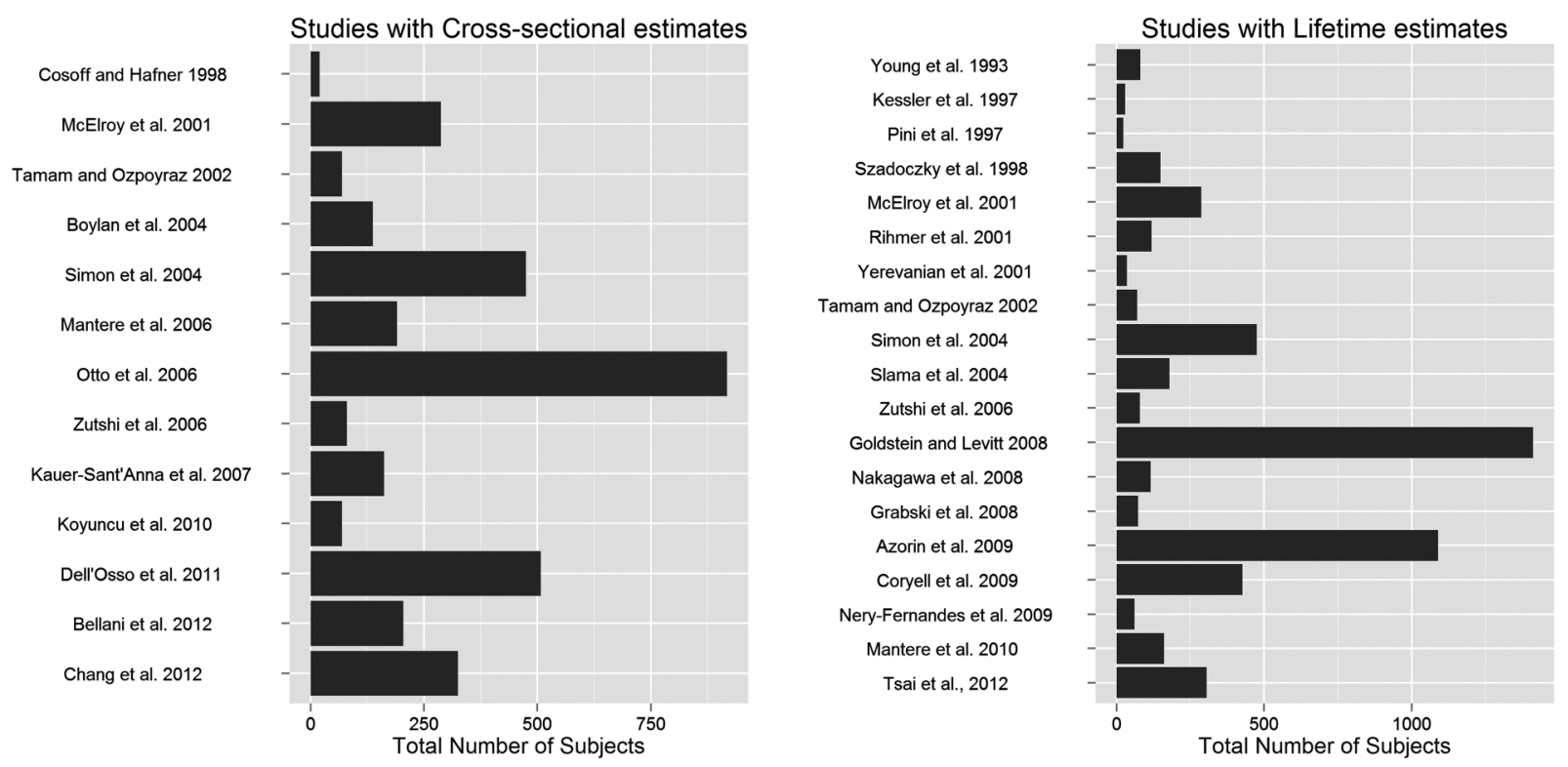

Figure 2 Sample size of studies on the prevalence of generalised anxiety disorder in patients with bipolar disorder. 
Table 1 Characteristics of studies included in meta-analysis concerning the point prevalence of GAD in BD

\begin{tabular}{|c|c|c|c|c|c|c|c|c|c|}
\hline Study & Location & $\begin{array}{l}\text { Diagnostic } \\
\text { group }\end{array}$ & $\begin{array}{l}\text { Criteria for } \\
\text { diagnosis }\end{array}$ & $\begin{array}{l}\text { Procedure for } \\
\text { diagnosis }\end{array}$ & $\mathbf{N}$ & $\begin{array}{l}\text { Males } \\
(\%)\end{array}$ & Age & $\begin{array}{l}\text { Prevalence } \\
\mathrm{N}(\%)\end{array}$ & Comments \\
\hline Bellani et $\left.a\right|^{38}$ & $\begin{array}{l}\text { University of Texas Health Science Center at } \\
\text { San Antonio, USA }\end{array}$ & $\begin{array}{l}\text { BD } \\
\text { MDD }\end{array}$ & DSM-IV & SCID & $\begin{array}{l}205 \\
105\end{array}$ & $\begin{array}{l}29.3 \\
29.5\end{array}$ & $\begin{array}{l}36.6 \pm 11.5 \\
38.0 \pm 13.1\end{array}$ & $\begin{array}{l}28(13.7) \\
4(3.8)\end{array}$ & Similar rates of depressive episodes between study groups \\
\hline Boylan et $a l^{39}$ & $\begin{array}{l}\text { McMaster Regional Mood Disorders Program } \\
\text { (Hamilton, Ontario, Canada }\end{array}$ & BD & DSM-IV & SCID & 138 & 31.9 & $\sim 41^{*}$ & $43(31.2)$ & Outpatients, $70.3 \%$ BD-I, $29.7 \%$ rapid cycling \\
\hline Chang et $a l^{40}$ & $\begin{array}{l}\text { National Cheng Kung University Hospital and } \\
\text { Tri-Service General Hospital, Taiwan }\end{array}$ & $\begin{array}{l}\text { BD-I } \\
\text { BD-II }\end{array}$ & DSM-IV-TR & SADS-L & $\begin{array}{l}120 \\
205\end{array}$ & $\begin{array}{l}48.33 \\
49.27\end{array}$ & $\begin{array}{l}31.4 \pm 11.5 \\
33.0 \pm 12.0\end{array}$ & $\begin{array}{l}10(8.33) \\
29(14.14)\end{array}$ & Outpatients from the Han population of Taiwan \\
\hline Cosoff and Hafner ${ }^{41}$ & Adelaide, Australia & $\begin{array}{l}\text { BD } \\
\text { Schiz } \\
\text { Schizoaff }\end{array}$ & DSM-III-R & SCID & $\begin{array}{l}20 \\
60 \\
20\end{array}$ & 60 & $34.8 \pm 10$ & $\begin{array}{l}2(10.0) \\
7(11.7) \\
2(10.0\end{array}$ & \\
\hline Dell'0sso et al ${ }^{42}$ & $\begin{array}{l}\text { University Department of Psychiatry of Milan, } \\
\text { Italy }\end{array}$ & BD & DSM-IV & SCID & 508 & 44.1 & $>40^{*}$ & $7(1.4)$ & $56.7 \%$ BD-I, $76.1 \%$ without any substance or alcohol abuse \\
\hline $\begin{array}{l}\text { Kauer-Sant'Anna } \\
\text { et } a^{{ }^{33}}\end{array}$ & $\begin{array}{l}\text { Bipolar Disorders Program of the University } \\
\text { Hospital at the Federal University, Porto Alegre, } \\
\text { Brazil }\end{array}$ & BD & DSM-IV-TR & SCID & 162 & 33.95 & $>42^{*}$ & $19(11.7)$ & Outpatients of University hospital \\
\hline Koyuncu et $a l^{44}$ & $\begin{array}{l}\text { Mood Disorders Unit of Psychiatry Department } \\
\text { of Istanbul Faculty of Medicine, Istanbul } \\
\text { University, Turkey }\end{array}$ & $\mathrm{BD}$ & DSM-IV & SCID & 70 & 35.7 & $36.2 \pm 15.9$ & $4(5.71)$ & Outpatients of University hospital \\
\hline Mantere et $a d^{45}$ & $\begin{array}{l}\text { Mood Disorders Research Unit, NPHI, Helsinki, } \\
\text { Finland }\end{array}$ & $\begin{array}{l}\mathrm{BD} \\
\mathrm{MDD}\end{array}$ & DSM-IV & SCID & $\begin{array}{l}191 \\
269\end{array}$ & $\begin{array}{l}47.1 \\
26.8\end{array}$ & $\begin{array}{l}37.7 \pm 12.2 \\
\mathrm{NA}\end{array}$ & $\begin{array}{l}29(15.18) \\
37(13.75)\end{array}$ & $\begin{array}{l}\text { Acute phase } \mathrm{BD}, 47.1 \% \mathrm{BD}-\mathrm{I} \text {, inpatients or outpatients. rapid cycling in } \\
32.5 \% \text {, and psychotic symptoms in } 16.2 \% \text { of patients }\end{array}$ \\
\hline McElroy et a ${ }^{6}$ & Multisite USA and the Netherlands & $\mathrm{BD}$ & DSM-IV & SCID & 288 & 44.0 & $42.8 \pm 11.3$ & $8(2.78)$ & STANLEY foundation data \\
\hline Simon et $a l^{12}$ & Multisite USA & $\begin{array}{l}\text { BD-I } \\
\text { BD-II }\end{array}$ & DSM-IV & SCID & $\begin{array}{l}360 \\
115\end{array}$ & 40.6 & $41.7 \pm 12.8$ & $\begin{array}{l}46(12.8) \\
12(10.4)\end{array}$ & First 500 patients of STEP-BD \\
\hline Otto et $a l^{46}$ & Multisite USA & $\mathrm{BD}$ & DSM-IV & SCID & 918 & 41.0 & $40.6 \pm 12.7$ & $122(13.3)$ & $\begin{array}{l}\text { First } 1000 \text { patients of STEP-BD. }>75 \% \text { BD-I, half patients in recovery, } \\
\sim 25 \% \text { depressed }\end{array}$ \\
\hline $\begin{array}{l}\text { Tamam and } \\
\text { Ozpoyraz }{ }^{47}\end{array}$ & Cucurova University Adana, Turkey & BD-I & DSM-IV & SCID & 70 & 41.4 & $33.4 \pm 10.3$ & $9(12.9)$ & Included only patients with BD-I \\
\hline \multirow[t]{2}{*}{ Zutshi et $a l^{48}$} & NIMHANS, Bangalore, India & $\mathrm{BD}$ & DSM-IV & SCID & 80 & 71.3 & $\begin{array}{l}30.06 \\
\pm 7.77\end{array}$ & $19(23.8)$ & $\begin{array}{l}\text { Patients with remitted BD; the controls were relatives of neurological } \\
\text { patients }\end{array}$ \\
\hline & & Controls & & & 50 & 76.0 & $\begin{array}{l}31.44 \\
\pm 7.85\end{array}$ & $3(6)$ & \\
\hline Overall & & $\begin{array}{l}\text { BD } \\
\text { Controls } \\
\text { MDD } \\
\text { Schiz } \\
\text { Schizoaff }\end{array}$ & $\begin{array}{l}\text { DSM (III-R or } \\
\text { IV) }\end{array}$ & SCID but 1 & $\begin{array}{l}2975 \dagger \\
50 \\
374 \\
60 \\
20\end{array}$ & & & $\begin{array}{l}12.9 \\
6.0 \\
12.1 \neq \\
11.7 \\
10.0\end{array}$ & $\begin{array}{l}\mathrm{BD} \text { and } \mathrm{MD} \text { rates are after meta-analysis. Corrected prevalence of GAD in } \\
\text { controls is } 3 \% \text { and in schizophrenia and schizoaffective is approximately } \\
\text { equal to that of } \mathrm{BD}\end{array}$ \\
\hline
\end{tabular}

*Not available, estimated.

TThe patients from the Simon et $a l^{12}$ study were not included because they overlap with those of the 0 tto et al ${ }^{46}$ study.

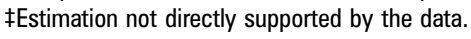

BD, bipolar disorder; DSM, Diagnostic and Statistical Manual of Mental Disorders; GAD, generalised anxiety disorder; N, sample size; NA, not available; MDD, major depressive disorder; SADS-L, Schedule for Affective Disorders and

Schizophrenia-Lifetime version; SCID, Structured Clinical Interview for DSM; Schiz, schizophrenia; Schizoaff, schizoaffective disorder. 
Table 2 Characteristics of studies included in meta-analysis concerning the lifetime prevalence of GAD in BD

\begin{tabular}{|c|c|c|c|c|c|c|c|c|c|}
\hline Study & Location & $\begin{array}{l}\text { Diagnostic } \\
\text { group }\end{array}$ & $\begin{array}{l}\text { Criteria for } \\
\text { diagnosis }\end{array}$ & $\begin{array}{l}\text { Procedure for } \\
\text { diagnosis }\end{array}$ & $\mathbf{N}$ & $\begin{array}{l}\text { Males } \\
(\%)\end{array}$ & Age & $\begin{array}{l}\text { Prevalence } \\
\text { N (\%) }\end{array}$ & Comments \\
\hline Azorin et $a l^{51}$ & 19 centres in France & BD-I & DSM-IV & SCID & 1090 & 42.0 & $43.0 \pm 14.0$ & $217(19.9)$ & Acutely manic hospitalised patients with BD-I \\
\hline Coryell et $a l^{14}$ & 5 academic centres, USA & $\mathrm{BD}$ & $\mathrm{RDC}$ & SADS, LIFE & 427 & 41.9 & $36.3 \pm N A$ & 20 (4.68) & Prospective follow-up of $17.4 \pm 8.4$ years \\
\hline $\begin{array}{l}\text { Goldstein and } \\
\text { Levitt }^{52}\end{array}$ & National Institute on Alcoholism and Alcohol Abuse, USA & BD-I & DSM-IV & NESARC & 1411 & 41.0 & $38.9 \pm N A$ & $346(24.5)$ & $\begin{array}{l}\text { 2001-2002 National Epidemiologic Survey, } \\
\text { USA }\end{array}$ \\
\hline Grabski et $a^{53}$ & Three outpatient settings, Krakow Poland & $\begin{array}{l}\text { BD-I } \\
\text { BD-II }\end{array}$ & DSM-IV & CIDI & $\begin{array}{l}50 \\
23\end{array}$ & 42.5 & $44.6 \pm 11.0$ & $\begin{array}{l}17(34.0) \\
6(26.1)\end{array}$ & Outpatients in remission \\
\hline Kessler et $a l^{2}$ & US epidemiological study & BD-I & DSM-III-R & CIDI & 29 & 58.6 & NA & $12(41.4)$ & National Comorbidity Study \\
\hline McElroy et al ${ }^{6}$ & Multisite USA and the Netherlands & $\mathrm{BD}$ & DSM-IV & SCID & 288 & 44.0 & $42.8 \pm 11.3$ & $8(2.8)$ & STANLEY foundation data \\
\hline Mantere et $a^{54}$ & $\begin{array}{l}\text { National Public Health Institute, Helsinki, and Department of } \\
\text { Psychiatry, Jorvi Hospital, HUCH, Espoo, Finland }\end{array}$ & $\mathrm{BD}$ & DSM-IV & SCID & 161 & 49.3 & $18-59$ & $18(11.2)$ & Jorvi Bipolar Study \\
\hline Nakagawa et $a^{55}$ & Japan and USA & $\mathrm{BD}$ & DSM-III-R & SCID & 116 & 34.5 & $38.9 \pm N A$ & $2(1.7)$ & $\begin{array}{l}\text { Depressed patients, } 57.8 \% \text { BD-I, } 68.1 \% \\
\text { inpatients }\end{array}$ \\
\hline $\begin{array}{l}\text { Nery-Fernandes } \\
\text { et } a^{56}\end{array}$ & General Hospital of the Federal University of Bahia, Brazil & $\mathrm{BD}$ & DSM-IV & SCID & 62 & 20.9 & $42.0 \pm 12.73$ & $8(12.9)$ & Mostly BD-I \\
\hline Pini et $a l^{57}$ & Pisa, Italy & $\begin{array}{l}\text { BD } \\
\text { MDD } \\
\text { Dysthymia }\end{array}$ & DSM-III-R & SCID & $\begin{array}{l}24 \\
38 \\
25\end{array}$ & $\begin{array}{l}45.4 \\
25.0 \\
37.5\end{array}$ & $\begin{array}{l}37.9 \pm 12.0 \\
47.0 \pm 15.0 \\
43.0 \pm 12.0\end{array}$ & $\begin{array}{l}8(33.3) \\
14(36.8) \\
16(64.0)\end{array}$ & Depressed patients \\
\hline Rihmer et $a^{58}$ & Hungarian epidemiological study & $\begin{array}{l}\text { BD-I } \\
\text { BD-II } \\
\text { MDD }\end{array}$ & DSM-III-R & DIS & $\begin{array}{l}95 \\
24 \\
443\end{array}$ & NA & $18-64$ & $\begin{array}{l}10(10.5) \\
5(20.8) \\
62(14.0)\end{array}$ & \\
\hline Simon et al ${ }^{12}$ & Multisite USA & $\begin{array}{l}\mathrm{BD}-\mathrm{I} \\
\mathrm{BD}-\mathrm{II}\end{array}$ & DSM-IV & SCID & $\begin{array}{l}360 \\
115\end{array}$ & 40.6 & $41.7 \pm 12.8$ & $\begin{array}{l}68(18.9) \\
19(16.5)\end{array}$ & First 500 patients of STEP-BD \\
\hline Slama et $a^{59}$ & Paris and Bordeaux, France & $\mathrm{BD}$ & DSM-IV & DIGS & 180 & NA & NA & $7(3.9)$ & Patients in remission \\
\hline Szadoczky et al ${ }^{60}$ & Hungarian epidemiological study & $\begin{array}{l}\mathrm{BD} \\
\mathrm{MDD}\end{array}$ & DSM-III-R & DIS & $\begin{array}{l}149 \\
443\end{array}$ & 44.0 & $18-64$ & $\begin{array}{l}22(14.4) \\
62(14.0)\end{array}$ & Epidemiological, rates weighted for sex \\
\hline $\begin{array}{l}\text { Tamam and } \\
\text { Ozpoyraz }\end{array}$ & Cucurova University Adana, Turkey & BD-I & DSM-IV & SCID & 70 & 41.4 & $33.4 \pm 10.3$ & $10(14.3)$ & Included only patients with BD-I \\
\hline Tsai et $a l^{61}$ & Taiwan & BD-I & DSM-IV & CIDI & 306 & 48.0 & $37.07 \pm 12.3$ & $37(12.1)$ & \\
\hline Yerevanian et al ${ }^{13}$ & Los Angeles, USA & $\begin{array}{l}\mathrm{BD} \\
\mathrm{MDD}\end{array}$ & DSM-III & $\begin{array}{l}\text { SCID, chart } \\
\text { review }\end{array}$ & $\begin{array}{l}35 \\
98\end{array}$ & $\begin{array}{l}51.4 \\
28.6\end{array}$ & $\sim 40$ & $\begin{array}{l}3(8.6) \\
22(22.5)\end{array}$ & Mostly BD-II \\
\hline Young et $a l^{16}$ & Clarke Institute of Psychiatry, Toronto, Canada & $\mathrm{BD}$ & RDC & SADS & 81 & 39.5 & $37.6(19-66)$ & $26(32.1)$ & \\
\hline Zutshi et $a l^{48}$ & NIMHANS, Bangalore, India & $\begin{array}{l}\text { BD } \\
\text { Controls }\end{array}$ & DSM-IV & SCID & $\begin{array}{l}80 \\
50\end{array}$ & $\begin{array}{l}71.3 \\
76.0\end{array}$ & $\begin{array}{l}30.06 \pm 7.77 \\
31.44 \pm 7.85\end{array}$ & $\begin{array}{l}20(25) \\
3(6)\end{array}$ & $\begin{array}{l}\text { Patients with remitted } \mathrm{BD} \text {; the controls were } \\
\text { relatives of neurological patients }\end{array}$ \\
\hline Overall & & $\begin{array}{l}\text { BD } \\
\text { BD-I } \\
\text { BD-II } \\
\text { Controls } \\
\text { MDD } \\
\text { Dysthymia }\end{array}$ & $\begin{array}{l}\text { DSM III to IV } \\
\text { RDC }\end{array}$ & Various & $\begin{array}{l}4919 \\
3411 \\
162 \\
50 \\
579 \\
25\end{array}$ & & & $\begin{array}{l}15.1 \\
20.1 \\
12.5 \\
3-4^{*} \\
11.9^{*} \\
64.0\end{array}$ & \\
\hline
\end{tabular}

*Estimation not directly supported by the data.

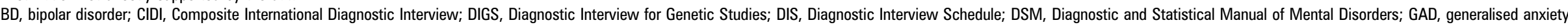

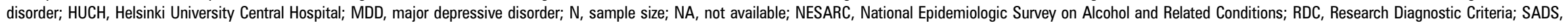

Schedule for Affective Disorders and Schizophrenia; SCID, Structured Clinical Interview for DSM. 


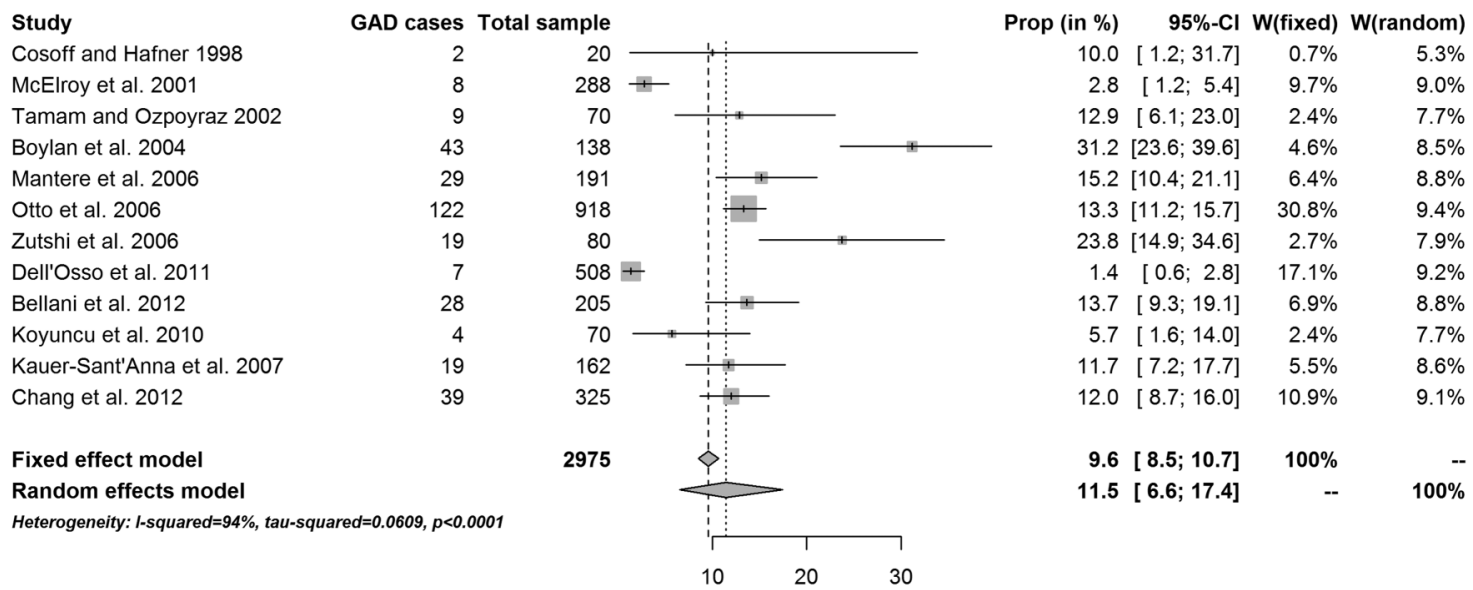

Figure 3 Point prevalence of generalised anxiety disorder $(G A D)$ in patients with bipolar disorder-W=individual study weight in both models.

to $18.6 \%)$. This later value should be considered to be the most appropriate to consider as the cross-sectional estimate. The fixed-effects lifetime estimate of GAD in patients diagnosed with $\mathrm{BD}$ was $15.8 \%(95 \%$ $\mathrm{Cl} 14.8 \%$ to $16.9 \%)$. The overall random-effects lifetime estimate of $\mathrm{GAD}$ in patients diagnosed with BD was $15.1 \% 195 \% \mathrm{Cl} 9.7 \%$ to $21.5 \%)$. Again, lifetime prevalence of GAD varied across studies, depending on the characteristics of the samples (figure 4). Heterogeneity was substantial: $I^{2}=94.7 \%$ (95\% Cl $92.8 \%$ to $96.0 \%$ ). The results suggest that the random-effects model was more appropriate for this data set. There was a trend for samples with BD type I to have a higher lifetime prevalence of $\mathrm{GAD}$, while samples with $\mathrm{BD}$ type II had a trend for a lower lifetime prevalence of GAD $(20.1 \%$ vs $12.5 \%$, table 3).

\section{DISCUSSION}

Although the literature is somewhat consistent concerning the overall high rates of comorbidity in patients with $\mathrm{BD}$, it is inconclusive concerning the rates of specific comorbid disorders. Methodological issues include the characteristics of the population being studied and the method of assessment. Epidemiological studies in the general population often use trained lay interviewers while clinical studies often use only highly experienced researchers. Thus, clinical samples are more reliably evaluated, but they might include patients with a more severe form of the illness. In contrast, general population samples have problematic assessment, which is done almost always with the use of structured interviews. This often leads to an artificial inflation of rates, because of false allocation or multiple allocation of the same symptom. ${ }^{18}$ However, some authors argue that population-based studies provide a better estimation of comorbidity rates compared with studies carried out in primary and secondary care settings, because the latter strategy introduces the bias of treatment-seeking into the sample. ${ }^{7}$ The current meta-analysis used data from 28 independent studies corresponding to a total of 2975 patients from point prevalence studies and 4919 patients from lifetime studies. It reports that the most probable point prevalence of $\mathrm{GAD}$ in patients with $\mathrm{BD}$ is $12.9 \%$ (irrespective of $\mathrm{BD}$ type), while the lifetime prevalence is $20.1 \%$ in patients with BD-I and $12.5 \%$ in patients with BD-II.

It is worth noting that in most studies point prevalence was a 12month prevalence and, because GAD is a chronic and relapsing disorder, this is probably the reason why point and lifetime prevalence resulted to be very close to each other in our analysis. In some instances, 'point' prevalence was higher than 'lifetime' prevalence as a result of different methodology, different quality of study samples and bias in the retrieval of information concerning past symptomatology.

Table 3 Effect sizes in meta-analysis of studies on GAD in BD

\begin{tabular}{|c|c|c|c|c|c|c|c|c|c|}
\hline & & $\mathbf{k}$ & $\mathbf{n}$ & Prevalence & $95 \% \mathrm{Cl}$ & 0 & p Value & $I^{2}(\%)$ & $95 \% \mathrm{Cl}$ \\
\hline \multirow[t]{5}{*}{ Point studies } & FE model & 12 & 2975 & $9.6 \%$ & $8.5 \%$ to $10.7 \%$ & & & & \\
\hline & RE model & 12 & 2975 & $11.5 \%$ & $6.6 \%$ to $17.4 \%$ & 182.1 & $<0.001$ & $94.0 \%$ & $91.2 \%$ to $95.9 \%$ \\
\hline & RE model without outliers & 11 & 2467 & $12.9 \%$ & $8.2 \%$ to $18.6 \%$ & 84.1 & $<0.001$ & $88.1 \%$ & $80.7 \%$ to $92.7 \%$ \\
\hline & RE in subgroup analysis 1 & 11 & 2785 & $11.6 \%$ & $6.2 \%$ to $18.3 \%$ & 183.4 & $<0.001$ & $94.5 \%$ & $92.0 \%$ to $96.3 \%$ \\
\hline & RE in subgroup analysis 2 & 12 & 2212 & $11.1 \%$ & $6.2 \%$ to $17.1 \%$ & 170.1 & $<0.001$ & $93.5 \%$ & $90.5 \%$ to $95.6 \%$ \\
\hline
\end{tabular}

Subgroup analysis 1: without Simon et $a l^{12}$ and Taman and Ozpoyraz ${ }^{40}$

Subgroup analysis 2: with BD-I subsample in Simon et al ${ }^{12}$ and without BD-Il subsample in Simon et al, ${ }^{12}$ BD-II subsample in Chang et al (2012) and 0tto et al (2006)

\begin{tabular}{|c|c|c|c|c|c|c|c|c|c|}
\hline \multirow[t]{5}{*}{ Lifetime studies } & FE model & 18 & 4919 & $15.8 \%$ & $14.8 \%$ to $16.9 \%$ & & & & \\
\hline & RE model & 18 & 4919 & $15.1 \%$ & $9.7 \%$ to $21.5 \%$ & 318.3 & $<0.001$ & $94.7 \%$ & $92.8 \%$ to $96.0 \%$ \\
\hline & RE in subgroup analysis 1 & 8 & 3411 & $20.1 \%$ & $12.7 \%$ to $28.7 \%$ & 48.8 & $<0.001$ & $85.7 \%$ & $73.7 \%$ to $92.2 \%$ \\
\hline & $\mathrm{RE}$ in subgroup analysis 2 & 13 & 1616 & $12.5 \%$ & $6.4 \%$ to $20.1 \%$ & 122.3 & $<0.001$ & $90.2 \%$ & $85.1 \%$ to $93.6 \%$ \\
\hline & RE in subgroup analysis 3 & 11 & 1603 & $11.2 \%$ & $5.0 \%$ to $19.4 \%$ & 110.8 & $<0.001$ & $91.0 \%$ & $85.9 \%$ to $94.2 \%$ \\
\hline
\end{tabular}

$k=$ number of included studies

$\mathrm{n}=$ number of patients in the included studies

Subgroup analysis 1: with BD-I samples only

Subgroup analysis 2: with BD-II and mixed samples

Subgroup analysis 3: with mixed samples only

$\mathrm{BD}$, bipolar disorder; FE, fixed-effects model; GAD, generalised anxiety disorders;

$\mathrm{RE}$, random-effects model with Bayesian estimator. 


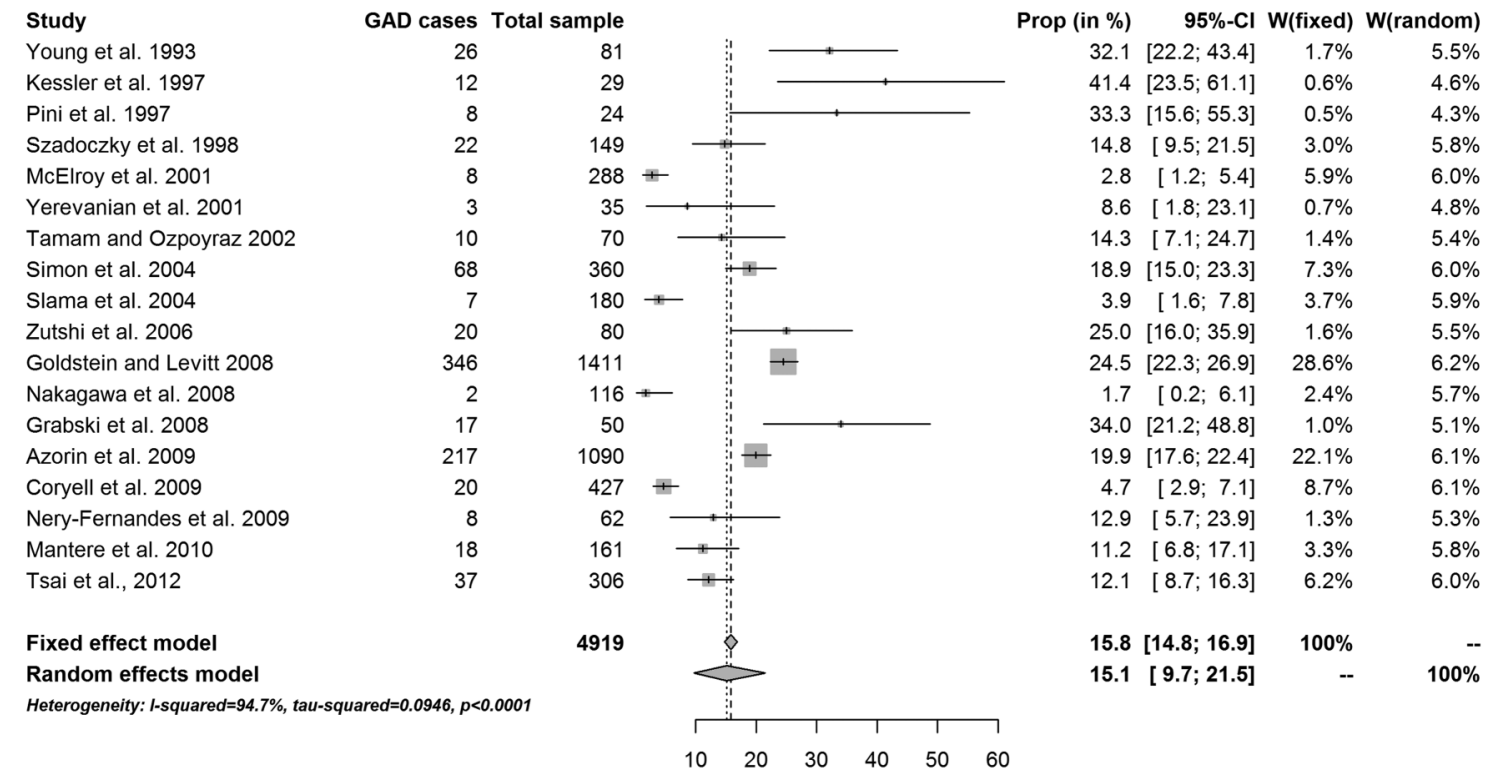

Figure 4 Lifetime prevalence of generalised anxiety disorder $(G A D)$ in patients with bipolar disorder-W=individual study weight in both models.

Published studies report prevalence rates with high heterogeneity; however, these rates are consistently higher than those typically reported in the general population. The rates vary across different study populations. It is possible that patients regularly admitted to hospital have higher rates of GAD than those treated primarily in the community. ${ }^{41}$ In one such study, ${ }^{39}$ a higher than usual frequency of comorbid in terms of point prevalence of GAD was reported. That study included patients from a specialised mood clinic with a focus on refractory mood disorders. The lowest rates of point prevalence of comorbid GAD were found in a study from Italy and the rate reported was $1.4 \%{ }^{42}$ while the highest rate concerned lifetime prevalence, which came from a study from the USA and was equal to $41.4 \%{ }^{2}$ The results of that study were based on 29 cases of patients with BD-I alone, which leads to imprecision in parameter estimates. Although it was a large general populationbased study with a total sample size of 8098 , the problem was that BD-I is rare in the general population, and this is why only 29 cases with $\mathrm{BD}$ were identified. Since the population in this study consisted of BD-I only, the generalisation of the findings to the whole group of patients with $\mathrm{BD}$ is questionable. The literature regarding the stronger association of $\mathrm{GAD}$ to specific $\mathrm{BD}$ types is inconsistent. In one study, GAD was found to be more strongly associated with BD-II than BD-I, with rates being $20.8 \%$ vs $10.5 \%$, respectively. ${ }^{58}$ The major limiting factor in this study was the patients' recall bias of the history. Of course, this is not a problem unique to that study. However, owing to this bias, many patients with BD-II might be classified as unipolars and therefore not included in such studies. In contrast, there are studies reporting that GAD is more strongly associated with BD-I. ${ }^{12}$

$\mathrm{GAD}$ is found to be highly comorbid with other mental disorders. Major depressive disorder (MDD) and GAD have the highest comorbidity rates to each other of all other mood and anxiety disorders. ${ }^{62}$ In the National Comorbidity Survey (NCS), 67\% of individuals with GAD also reported comorbid MDD, and $20 \%$ of individuals with MDD reported comorbid GAD. ${ }^{63}$ In another study of 1127 outpatients, it was found that current and lifetime anxiety and mood disorders are $57 \%$ and $81 \%$, respectively. ${ }^{62}$ High prevalence rates for anxiety disorder in people with psychosis are also reported, although the rates vary strikingly across the studies. Pooled prevalence rates of cooccurrence of GAD in schizophrenia in 52 studies were $9.8 \%(4.3 \%$ to $15.4 \%) .{ }^{64}$ It is also reported that over $30 \%$ of adults with obsessive-compulsive disorder have a lifetime history of GAD. ${ }^{65} 66$
There is no clear consensus on the role of sociodemographic variables on the comorbid prevalence of $\mathrm{GAD}$ in cases with $\mathrm{BD}$, and often the studies use a vague 'anxiety' variable rather than a precise GAD diagnostic category. In some studies, an association between female gender $^{47} 6768$ or younger age ${ }^{39}$ was reported; however, negative reports also exist. ${ }^{16} 5969$ Some studies reported a relationship of anxiety comorbidity with earlier age at onset of BD.6 12396970 This may be due to the fact that sometimes anxiety disorders seem to precede bipolar illness and therefore hasten its outbreak, whereas in other cases they may occur afterwards. In contrast, there are studies that do not find such a relationship. ${ }^{51}$

Comorbid GAD might be associated with a more severe BD course, more past depressive episodes, less interepisode recovery and poorer response to acute phase treatment, and a need for more numbers of mood stabilisers for acute management. ${ }^{71}$ The study of 135 patients with GAD with or without other anxiety and mood disorders found that when GAD was comorbid with any other disorder, the chance of remission was three times less than when GAD was absent. ${ }^{72}$ Also, it has been reported that an independent association of comorbid anxiety with greater severity and impairment was demonstrated in patients with $\mathrm{BD}$ across all phases of the illness. ${ }^{12}$ Anxiety has also been related to more severe illness in another study, having important consequences regarding symptom-rated and patient-rated outcomes. ${ }^{73-75}$ An association of the presence of anxiety symptoms with greater severity of manic symptoms and longer hospitalisations was demonstrated. ${ }^{76}$ Patients can experience work, family, social impairment and increased healthcare costs and strains on family support. ${ }^{73}$ Patients with $\mathrm{BD}$ with high anxiety levels tend to have a greater proportion of weeks in major depressive episodes and a lesser proportion of weeks in manic or hypomanic episodes. ${ }^{14} \mathrm{~A}$ relationship between additional anxiety and depressive symptomatology was reported in many of the previous studies. ${ }^{47} 677077$ Current depression but not mania could predict comorbid anxiety disorders and poorer treatment response. ${ }^{67}$ Some authors report that the presence of anxiety is strongly associated with higher impulsivity in mood disorders. ${ }^{38} 78$ Impulsivity may relate differently to dangerous behaviours like suicidality and substance use in bipolar illness. This relationship may be responsible for the higher number of suicide attempts found in the population of comorbid anxiety in patients with $\mathrm{BD}{ }^{80}$

It is well known that comorbid $\mathrm{GAD}$ and $\mathrm{BD}$ are often treated with benzodiazepines (BZDs) that have some benefits for patients with BD, but 
they may also lead to or exacerbate substance abuse. The 5-year prevalence of BZD use among patients with BD with and without comorbid substance use disorder was reported to be $75 \%$ and $58 \%$, respectively. ${ }^{81}$ Moreover, adjunctive BZD use at the time of symptom remission has been linked with higher risk of mood episode recurrence, as compared with no BZD use, in patients with BD-I and BD-II. ${ }^{82}$ However, some studies report no significant effect of BZD use on any outcome measure in patients with $\mathrm{BD}$ with comorbid anxiety or substance use disorders. ${ }^{83}$ Furthermore, in some studies, BZDs are suggested as a possible adjunctive therapy for extending follow-up and thus preventing recurrence in patients with $\mathrm{BD}^{84}$ On the other hand, the data are positive concerning the usefulness of quetiapine $(50-600 \mathrm{mg} / \mathrm{day}))^{85-89}$ lurasidone $(20-120 \mathrm{mg} / \text { day })^{90}$ and paroxetine $(20 \mathrm{mg} / \text { day })^{89}$ but not divalproex $(500-3000 \mathrm{mg} / \mathrm{day}){ }^{88}$ risperidone $(0.5-4 \mathrm{mg} / \mathrm{day})^{91}$ or ziprasidone. ${ }^{92}$ Although approved for the treatment of GAD, gabapentine has no data concerning the treatment of anxiety in patients with $B D$ and has negative data concerning its use against acute mania. ${ }^{93} 94$

One interesting and also important feature of this study is that only onequarter (7 out of 30) papers were identified through the MEDLINE search while the rest were identified by the careful and laborious scanning of reference lists of review papers and books. The reason for this is not entirely clear, but at least partially it is because the data were hidden in studies with different aims and scope; therefore, the key words did not work. This leads to two inevitable conclusions: first, one could not be sure that more such studies exist and remain to be identified, and second, the reliability and validity of review and meta-analytic studies, including the current one, is problematic.

An important methodological limitation concerns the method most studies used to diagnose comorbid disorders. Although a comorbid anxiety disorder should only be diagnosed in BD if its symptoms occur independently of mood symptoms, this was probably not the case in most studies which probably used a simple DSM criteria approach. It is important to note that in no DSM edition is there a requirement for symptoms and diagnosis to be independent; therefore, in most instances, it is highly likely that GAD symptoms overlapped with those of $\mathrm{BD}$.

In conclusion, this meta-analysis confirms that GAD is highly prevalent in $\mathrm{BD}$ and the prevalence rates are higher than those reported in the general population, but it also highlights the great variations in rates among studies. Identifying and treating GAD can be clinically significant in order to lessen BD severity, improve response to treatment of manic or depressive symptoms and reduce suicidality.

- Additional material is published online only. To view please visit the journal online (http://dx.doi.org/10.1136/eb-2016-102412)

Contributions KF and AP conceptualized and designed the study. AP, and JV drafted the manuscript. AP, JV, AAV, TBHM, and KF critically reviewed the manuscript as submitted.

Funding AAV is funded by the Banting Postdoctoral Fellowship Program from the Canadian Institutes of Health Research.

Competing interests None declared.

Provenance and peer review Not commissioned; externally peer reviewed. doi:10.1136/eb-2016-102412

Received 1 June 2016; Revised 13 June 2016; Accepted 13 June 2016

\section{REFERENCES}

1. Wittchen HU. Critical issues in the evaluation of comorbidity of psychiatric disorders. Br J Psychiatry Supp/ 1996;30:9-16.

2. Kessler RC, Rubinow DR, Holmes C, et al. The epidemiology of DSM-III-R bipolar I disorder in a general population survey. Psychol Med 1997;27:1079-89.

3. Vieta $\mathbf{E}$, Colom F, Corbella B, et al. Clinical correlates of psychiatric comorbidity in bipolar I patients. Bipolar Disord 2001;3:253-8.

4. Krishnan KRR. Psychiatric and medical comorbidities of bipolar disorder. Psychosom Med 2005;67:1-8.
5. Leverich GS, Altshuler LL, Frye MA, et al. Factors associated with suicide attempts in 648 patients with bipolar disorder in the Stanley Foundation Bipolar Network. J Clin Psychiatry 2003:64:506-15.

6. McElroy SL, Altshuler LL, Suppes T, et al. Axis I psychiatric comorbidity and its relationship to historical illness variables in 288 patients with bipolar disorder. Am J Psychiatry 2001;158:420-6.

7. Sasson $\mathbf{Y}$, Chopra M, Harrari E, et al. Bipolar comorbidity: from diagnostic dilemmas to therapeutic challenge. Int J Neuropsychopharmacol 2003;6:139-44.

8. Subramaniam M, Abdin E, Vaingankar JA, et al. Prevalence, correlates, comorbidity and severity of bipolar disorder: results from the Singapore Mental Health Study. J Affect Disord 2013;146:189-96.

9. Blacker D, Tsuang MT. Contested boundaries of bipolar disorder and the limits of categorical diagnosis in psychiatry. Am J Psychiatry 1992;149:1473-83.

10. Zarate CA, Tohen M. Bipolar disorder and comorbid axis I disorders. In: Tohen M, ed. Comorbidity in affective disorders. New York: Marcel Dekker, 1999: 229-39.

11. Wittchen HU, Jacobi F, Rehm J, et al. The size and burden of mental disorders and other disorders of the brain in Europe 2010. Eur Neuropsychopharmacol 2011;21:655-79.

12. Simon NM, Otto MW, Wisniewski SR, et al. Anxiety disorder comorbidity in bipolar disorder patients: data from the first 500 participants in the Systematic Treatment Enhancement Program for Bipolar Disorder (STEP-BD). Am J Psychiatry 2004;161:2222-9.

13. Yerevanian BI, Koek RJ, Ramdev S. Anxiety disorders comorbidity in mood disorder subgroups: data from a mood disorders clinic. J Affect Disord 2001;67: 167-73.

14. Coryell W, Solomon DA, Fiedorowicz JG, et al. Anxiety and outcome in bipolar disorder. Am J Psychiatry 2009;166:1238-43.

15. Feske U, Frank E, Mallinger AG, et al. Anxiety as a correlate of response to the acute treatment of bipolar I disorder. Am J Psychiatry 2000;157:956-62.

16. Young LT, Cooke RG, Robb JC, et al. Anxious and non-anxious bipolar disorder. $J$ Affect Disord 1993;29:49-52.

17. Moher $\mathbf{D}$, Liberati A, Tetzlaff J, et al. Preferred reporting items for systematic reviews and meta-analyses: the PRISMA statement. Int J Surg 2010;8:336-41.

18. Fountoulakis KN. Bipolar disorder: an evidence-based guide to manic depression. Springer, 2015.

19. Goodwin F, Jamison K. Manic-depressive illness. 2nd edn. New York: Oxford University Press, 2007

20. Nabavi B, Mitchell AJ, Nutt D. A lifetime prevalence of comorbidity between bipolar affective disorder and anxiety disorders: a meta-analysis of 52 interview-based studies of psychiatric population. EBioMedicine 2015;2:1405-19.

21. Freeman M, Tukey J. Transformations related to the angular and the square root. Ann Math Stat 1950:4.

22. Barendregt JJ, Doi SA, Lee $\mathrm{YY}$, et al. Meta-analysis of prevalence. J Epidemiol Community Health 2013;67:974-8.

23. Miller J. The inverse of the Freeman-Tukey double arcsine transformation. Am Stat 1978:32.

24. Morris CN. Parametric empirical Bayes inference: theory and applications (with discussion). J Am Stat Assoc 1983:78:47-55.

25. Paule RC, Mandel J. Consensus values and weighting factors. J Res Natl Bur Stand 1982;87:377-85.

26. Viechtbauer W. Confidence intervals for the amount of heterogeneity in meta-analysis. Stat Med 2007;26:37-52.

27. Knapp G, Hartung J. Improved tests for a random effects meta-regression with a single covariate. Stat Med 2003;22:2693-710.

28. Huedo-Medina TB, Sánchez-Meca J, Marín-Martínez F, et al. Assessing heterogeneity in meta-analysis: 0 statistic or 12 index? Psychol Methods 2006;11:193-206.

29. Higgins JPT, Thompson SG, Deeks JJ, et al. Measuring inconsistency in meta-analyses. BMJ 2003;327:557-60.

30. Egger M, Davey Smith G, Schneider M, et al. Bias in meta-analysis detected by a simple, graphical test. BMJ 1997;315:629-34.

31. Begg CB, Mazumdar M. Operating characteristics of a rank correlation test for publication bias. Biometrics 1994;50:1088-101.

32. Baujat B, Mahé C, Pignon JP, et al. A graphical method for exploring heterogeneity in meta-analyses: application to a meta-analysis of 65 trials. Stat Med 2002;21:2641-52.

33. Galbraith RF. A note on graphical presentation of estimated odds ratios from several clinical trials. Stat Med 1988;7:889-94.

34. Galbraith R. Some applications of radial plots. J Am Stat Assoc 1994;89:1232-42.

35. Viechtbauer $\mathbf{W}$. Conducting meta-analyses in $\mathrm{R}$ with the metafor package. J Stat Softw 2010:1-48.

36. Schwarzer G. Meta-Analysis with R. R package version 3.7-1, 2014.

37. R Core T. R: A language and environment for statistical computing. Vienna, Austria, R Foundation for Statistical Computing, 2013.

38. Bellani M, Hatch JP, Nicoletti MA, et al. Does anxiety increase impulsivity in patients with bipolar disorder or major depressive disorder? J Psychiatr Res 2012;46:616-21. 
39. Boylan KR, Bieling PJ, Marriott M, et al. Impact of comorbid anxiety disorders on outcome in a cohort of patients with bipolar disorder. J Clin Psychiatry 2004;65:1106-13.

40. Chang YH, Chen SL, Chen SH, et al. Low anxiety disorder comorbidity rate in bipolar disorders in Han Chinese in Taiwan. Prog Neuropsychopharmacol Biol Psychiatry 2012;36:194-7.

41. Cosoff SJ, Hafner RJ. The prevalence of comorbid anxiety in schizophrenia, schizoaffective disorder and bipolar disorder. Aust N Z J Psychiatry 1998;32:67-72.

42. Dell'Osso B, Buoli M, Bortolussi S, et al. Patterns of axis I comorbidity in relation to age in patients with bipolar disorder: a cross-sectional analysis. J Affect Disord 2011;130:318-22.

43. Kauer-Sant'Anna M, Frey BN, Andreazza AC, et al. Anxiety comorbidity and quality of life in bipolar disorder patients. Can J Psychiatry 2007:52:175-81.

44. Koyuncu A, Tukel R, Ozyildirim I, et al. Impact of obsessive-compulsive disorder comorbidity on the sociodemographic and clinical features of patients with bipolar disorder. Compr Psychiatry 2010;51:293-7.

45. Mantere 0, Melartin TK, Suominen K, et al. Differences in Axis I and II comorbidity between bipolar I and II disorders and major depressive disorder. J Clin Psychiatry 2006;67:584-93

46. Otto MW, Simon NM, Wisniewski SR, et al. Prospective 12-month course of bipolar disorder in out-patients with and without comorbid anxiety disorders. $\mathrm{Br} \mathrm{J}$ Psychiatry: J Ment Sci 2006;189:20-25.

47. Tamam L, Ozpoyraz N. Comorbidity of anxiety disorder among patients with bipolar I disorder in remission. Psychopathology 2002;35:203-9.

48. Zutshi A, Reddy YCJ, Thennarasu K, et al. Comorbidity of anxiety disorders in patients with remitted bipolar disorder. Eur Arch Psychiatry Clin Neurosci 2006;256:428-36.

49. Simon NM, Zalta AK, Otto MW, et al. The association of comorbid anxiety disorders with suicide attempts and suicidal ideation in outpatients with bipolar disorder. J Psychiatr Res 2007;41:255-64.

50. Simon NM, Smoller JW, Fava M, et al. Comparing anxiety disorders and anxiety-related traits in bipolar disorder and unipolar depression. J Psychiatr Res 2003;37:187-92

51. Azorin JM, Kaladjian A, Adida M, et al. Psychopathological correlates of lifetime anxiety comorbidity in bipolar I patients: findings from a French national cohort. Psychopathology 2009:42:380-6.

52. Goldstein BI, Levitt AJ. The specific burden of comorbid anxiety disorders and of substance use disorders in bipolar I disorder. Bipolar Disorders 2008;10:67-78.

53. Grabski B, Dudek D, Datka W, et al. Lifetime anxiety and substance use disorder comorbidity in bipolar disorder and its relationship to selected variables. Gender and bipolar subtype differences in comorbidity. Arch Psychiatry Psychother 2008;3:5-15.

54. Mantere $\mathbf{0}$, Isometsa E, Ketokivi M, et al. A prospective latent analyses study of psychiatric comorbidity of DSM-IV bipolar I and II disorders. Bipolar Disord 2010;12:271-84.

55. Nakagawa A, Grunebaum MF, Sullivan GM, et al. Comorbid anxiety in bipolar disorder: does it have an independent effect on suicidality? Bipolar Disorders 2008;10:530-38.

56. Nery-Fernandes F, Quarantini LC, Galvao-De-Almeida A, et al. Lower rates of comorbidities in euthymic bipolar patients. World J Biol Psychiatry 2009;10:474-9.

57. Pini S, Cassano GB, Simonini E, et al. Prevalence of anxiety disorders comorbidity in bipolar depression, unipolar depression and dysthymia. J Affect Disord 1997;42:145-53.

58. Rihmer Z, Szádóczky E, Füredi J, et al. Anxiety disorders comorbidity in bipolar I, bipolar II and unipolar major depression: results from a population-based study in Hungary. J Affect Disord 2001;67:175-9.

59. Slama F, Bellivier F, Henry C, et al. Bipolar patients with suicidal behavior: toward the identification of a clinical subgroup. J Clin Psychiatry 2004:65:1035-9.

60. Szádóczky E, Papp Zs, Vitrai J, et al. The prevalence of major depressive and bipolar disorders in Hungary. Results from a national epidemiologic survey. $J$ Affect Disord 1998;50:153-62.

61. Tsai HC, Lu MK, Yang YK, et al. Empirically derived subgroups of bipolar I patients with different comorbidity patterns of anxiety and substance use disorders in Han Chinese population. J Affect Disord 2012;136:81-9.

62. Brown TA, Campbell LA, Lehman CL, et al. Current and lifetime comorbidity of the DSM-IV anxiety and mood disorders in a large clinical sample. J Abnorm Psychol 2001:110:585-99.

63. Kessler RC, DuPont RL, Berglund P, et al. Impairment in pure and comorbid generalized anxiety disorder and major depression at 12 months in two national surveys. Am J Psychiatry 1999;156:1915-23.

64. Achim AM, Maziade M, Raymond É, et al. How prevalent are anxiety disorders in schizophrenia? A meta-analysis and critical review on a significant association. Schizophr Bull 2011;37:811-21.

65. Andrews G, Neilson M, Hunt C, et al. Diagnosis, personality and the long-term outcome of depression. Br J Psychiatry 1990;157:13-18.

66. Pigott TA, L'Heureux F, Dubbert B, et al. Obsessive compulsive disorder: comorbid conditions. J Clin Psychiatry 1994;55(Suppl):15-27.

67. Gaudiano BA, Miller IW. Anxiety disorder comorbidity in bipolar I disorder: relationship to depression severity and treatment outcome. Depress Anxiety 2005:21:71-7.
68. Strakowski SM, Sax KW, McElroy SL, et al. Course of psychiatric and substance abuse syndromes co-occurring with bipolar disorder after a first psychiatric hospitalization. J Clin Psychiatry 1998;59:465-71.

69. Henry C, Van den Bulke D, Bellivier F, et al. Anxiety disorders in 318 bipolar patients: prevalence and impact on illness severity and response to mood stabilizer. J Clin Psychiatry 2003;64:331-5.

70. Bauer MS, Altshuler L, Evans DR, et al. Prevalence and distinct correlates of anxiety, substance, and combined comorbidity in a multi-site public sector sample with bipolar disorder. J Affect Disord 2005;85:301-15

71. Das A. Anxiety disorders in bipolar I mania: prevalence, effect on illness severity, and treatment implications. Indian J Psychol Med 2013;35:53-9.

72. Yonkers KA, Warshaw MG, Massion A0, et al. Phenomenology and course of generalised anxiety disorder. Br J Psychiatry 1996;168:308-13.

73. Keller MB. Prevalence and impact of comorbid anxiety and bipolar disorder. J Clin Psychiatry 2006;67:5-7.

74. Magalhães PVS, Kapczinski NS, Kapczinski F. Correlates and impact of obsessive-compulsive comorbidity in bipolar disorder. Compr Psychiatry 2010;51:353-6.

75. Toniolo RA, Caetano SC, da Silva PV, et al. Clinical significance of lifetime panic disorder in the course of bipolar disorder type I. Compr Psychiatry 2009;50:9-12.

76. González-Pinto A, Galán J, Martín-Carrasco M, et al. Anxiety as a marker of severity in acute mania. Acta Psychiatr Scand 2012:126:351-5.

77. Frank E, Cyranowski JM, Rucci P, et al. Clinical significance of lifetime panic spectrum symptoms in the treatment of patients with bipolar I disorder. Arch Gen Psychiatry 2002;59:905-11

78. Perugi G, Del Carlo A, Benvenuti $\mathrm{M}$, et al. Impulsivity in anxiety disorder patients: is it related to comorbid cyclothymia? J Affect Disord 2011;133:600-6.

79. Taylor CT, Hirshfeld-Becker DR, Ostacher MJ, et al. Anxiety is associated with impulsivity in bipolar disorder. J Anxiety Disord 2008;22:868-76.

80. Dilsaver SC, Akiskal HS, Akiskal KK, et al. Dose-response relationship between number of comorbid anxiety disorders in adolescent bipolar/unipolar disorders, and psychosis, suicidality, substance abuse and familiality. J Affect Disord 2006;96:249-58.

81. Clark RE, Xie H, Brunette MF. Benzodiazepine prescription practices and substance abuse in persons with severe mental illness. J Clin Psychiatry 2004;65:151-5.

82. Perlis RH, Ostacher MJ, Miklowitz DJ, et al. Benzodiazepine use and risk of recurrence in bipolar disorder: a STEP-BD report. J Clin Psychiatry 2010;71:194-200.

83. Bobo WV, Reilly-Harrington NA, Ketter TA, et al. Corrigendum to "Effect of adjunctive benzodiazepines on clinical outcomes in lithium- or quetiapine-treated outpatients with bipolar I or II disorder: results from the bipolar CHOICE trial" [J. Affect. Disord. 161 (2014) 30-35]. J Affect Disord 2014;167:259-60.

84. Gul H, Hag-Ryul K, Sang-Hag P, et al. Do benzodiazepines extend the duration of follow-up treatment in patients with bipolar disorder? Hum Psychopharmacol 2006:21:319-25.

85. Calabrese JR, Keck PE Jr, Macfadden W, et al. A randomized, double-blind, placebo-controlled trial of quetiapine in the treatment of bipolar I or II depression. Am J Psychiatry 2005;162:1351-60.

86. Thase ME, Macfadden W, Weisler RH, et al. Efficacy of quetiapine monotherapy in bipolar I and II depression: a double-blind, placebo-controlled study (the BOLDER || study). J Clin Psychopharmacol 2006;26:600-9.

87. Lydiard RB, Culpepper L, Schiöler H, et al. Quetiapine monotherapy as treatment for anxiety symptoms in patients with bipolar depression: a pooled analysis of results from 2 double-blind, randomized, placebo-controlled studies. Prim Care Companion J Clin Psychiatry 2009;11:215-25.

88. Sheehan DV, Harnett-Sheehan K, Hidalgo RB, et al. Randomized, placebo-controlled trial of quetiapine XR and divalproex ER monotherapies in the treatment of the anxious bipolar patient. J Affect Disord 2013;145:83-94

89. McElroy SL, Weisler RH, Chang W, et al. A double-blind, placebo-controlled study of quetiapine and paroxetine as monotherapy in adults with bipolar depression (EMBOLDEN II). J Clin Psychiatry 2010;71:163-74.

90. Loebel A, Cucchiaro J, Silva R, et al. Lurasidone monotherapy in the treatment of bipolar I depression: a randomized, double-blind, placebo-controlled study. Am J Psychiatry 2014;171:160-8.

91. Sheehan DV, McElroy SL, Harnett-Sheehan K, et al. Randomized, placebo-controlled trial of risperidone for acute treatment of bipolar anxiety. J Affect Disord 2009:115:376-85.

92. Suppes T, McElroy SL, Sheehan DV, et al. A randomized, double-blind, placebocontrolled study of ziprasidone monotherapy in bipolar disorder with co-occurring lifetime panic or generalized anxiety disorder. J Clin Psychiatry 2014;75:77-84.

93. Frye MA, Ketter TA, Kimbrell $T A$, et al. A placebo-controlled study of lamotrigine and gabapentin monotherapy in refractory mood disorders. J Clin Psychopharmacol 2000;20:607-14.

94. Pande AC, Crockatt JG, Janney CA, et al. Gabapentin in bipolar disorder: a placebo-controlled trial of adjunctive therapy. Gabapentin Bipolar Disorder Study Group. Bipolar Disord 2000;2:249-55. 